\title{
A FORMAÇÃO DE PROFESSORES A DISTÂNCIA COMO ESTRATÉGIA DE EXPANSÃO DO ENSINO SUPERIOR*
}

\author{
Raquel Goulart BarReto*
}

\begin{abstract}
RESUMO: Este artigo visa analisar estratégias de regulação para a expansão da formação de professores, focalizando os modos pelos quais as tecnologias da informação e da comunicação (TIC) têm sido recontextualizadas nas políticas educacionais. Para tanto, inclui: (1) os pressupostos, que tendem a não ser objeto de questionamento sistemático; (2) discursos e condições de possibilidade, enfatizando as mudanças contextuais para a sua articulação; (3) marcos regulatórios identificados nos documentos oficiais e nos movimentos para a sua operacionalização; (4) a educação a distância (EaD) como motor da expansão nos setores privado e público; e (5) a substituição tecnológica como chave para compreender o núcleo das políticas atuais.
\end{abstract}

Palavras-chave: Políticas educacionais. Formação de professores. Tecnologias da informação e da comunicação. Condiçôes de possibilidade. Substituição tecnológica.

\section{DISTANCE TEACHERS' TRAINING AS AN EXPANSION STRATEGY FOR HIGHER EDUCATION}

ABSTRACT: This paper analyzes the regulation strategies concerning the expansion of teachers' education. It focuses on the ways the Information and Communication Technologies (ICT) have been recontextualized in educational policies. To do so, it approaches: (1) assumptions that are not systematically questioned; (2) speeches and conditions of possibility, emphasizing

\footnotetext{
* Texto baseado em pesquisas com financiamentos do CNPq e da FAPERJ.

** Doutora em Educação e professora do Programa de Pós-Graduação em Educação da Universidade do Estado do Rio de Janeiro (UERJ). E-mail: raquel@uol.com.br
} 
the contextual changes in articulate them; (3) regulation strategies identified in official documents as well as in the movements to operationalize them; (4) distance learning as the expansion drive in both the private and the public sectors; and (5) the technological substitution as a key to grasp the core of current policies.

Key words: Educational policies. Teacher education. Information and communication technologies. Conditions of possibility. Technological substitution.

\section{Os pressupostos}

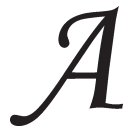

$s$ relações entre as tecnologias da informação e da comunicação (TIC) e a educação a distância (EaD) têm sido objeto de uma cadeia de simplificações fundadas em pressupostos nem sempre explicitados. O principal deles é o de que o mundo tenha mudado em função de uma "revolução científico-tecnológica", em cujo centro estariam as TIC. Nesta perspectiva determinista (Wood, 2003), as TIC podem ser pensadas fora das relações que constituem o contexto da sua produção, como se as extrapolassem ou mesmo transcendessem e, nesta condição, também pudessem instaurar uma espécie de "admirável mundo novo", caracterizado pelo apagamento das múltiplas determinações do real, favorecendo o que Mattelart (2006, p. 235) denominou "tese dos fins ou crepúsculos: fim das ideologias, do político em proveito do management, do fim dos intelectuais contestadores, em proveito da ascensão irresistível dos intelectuais 'positivos', orientados para a tomada de decisóes".

Em outras palavras, o determinismo tecnológico hipertrofia as mudanças introduzidas pelas TIC nas práticas sociais, do trabalho ao lazer, passando pelas formas de comunicação, no movimento de desconsiderar suas continuidades em relação às práticas anteriores, como a preservação dos poderes econômicos e políticos constituídos e o aprofundamento da divisão entre possuidores e despossuídos, no que tem sido posto como tecnocapitalismo global, em construçóes como capitalismo cognitivo, empreendedorismo etc. (Antunes \& Braga, 2009). A extrapolação de todos os limites fica mais evidente quando, em lugar do nome genérico (tecnologias) e da sigla (TIC), é usada a expressão completa: tecnologias da informação e da comunicação. Como 
discuto na seção seguinte, a expressão exige a análise dos modos da sua recontextualização em diferentes campos e escalas.

No campo da educação, o pressuposto de que as TIC, em si, constituem uma "revolução" tem desdobramentos importantes. Entre eles, merecem destaque as relaçóes estabelecidas com a EaD, em pelo menos três aspectos: (1) a associação direta (TIC para a EaD), fundada no movimento aparentemente contraditório de expansão-redução, supondo, de um lado, que as TIC sejam "a solução" para todos os problemas, incluindo os extraescolares, e, de outro, seu uso intensivo e quase exclusivo para a EaD, visando especialmente à certificação de professores; (2) a proposta de EaD como substituição tecnológica, apoiada na flexibilização gerencial, apagando as diferenças constitutivas dos modos de acesso às TIC; e (3) a suposta centralidade atribuída às TIC nas políticas educacionais, elidindo a perspectiva de formação baseada em competências, tanto na configuração dos processos, quanto como alternativa de triangulação para promover resultados, na condição de elo entre diretrizes ou parâmetros curriculares nacionais e avaliação centralizada.

Assumindo que as TIC podem contribuir significativamente para os processos educacionais, sem fetichização, é necessário questionar as razões pelas quais elas têm tido como destinação prioritária a EaD que, por sua vez, posta como "modalidade de ensino", suscita questóes relativas à sua configuração e objetivação, envolvendo os modos pelos quais ela tem sido pensada.

Não sendo posto em xeque o estatuto ora atribuído, aqui devidamente aspeado, a EaD pode ser objetivada a partir da sua especificidade em relação ao ensino presencial e, especialmente, em função do seu modus operandi (sendo a única não nomeada em função do nível de ensino ou da clientela a que se destina, mas ao modo da sua realização), podendo mesmo dispensar discussões substantivas, em função da centralidade das TIC para a veiculação dos materiais de ensino e para o seu gerenciamento. Por outro lado, partindo da constatação de que a EaD configura estratégia central nas políticas educacionais, a discussão, antes e para além de quaisquer considerações operacionais, precisa dar conta das várias dimensões da sua inscrição histórica.

A primeira perspectiva é hegemônica. A segunda sustenta os encaminhamentos a seguir, pretendendo contribuir para a abordagem dialética das relações privilegiadas no título. 


\section{Discursos e condições de possibilidade}

O presente encaminhamento das questões relativas à EaD como flexibilização estratégica assume a análise crítica de discurso (ACD) nos termos de Fairclough (2001; 2003a; 2003b; 2005; 2006; 2009; 2010) como alternativa teórico-metodológica. Para tanto, parte dos pressupostos, dos conceitos-chave e dos pontos de entrada selecionados.

Em nível de pressupostos, é fundamental dimensionar a investigação das práticas de linguagem como formas materiais da ideologia na perspectiva do realismo crítico, caracterizado por buscar objetivá-las nas suas múltiplas determinaçōes, na condição de prática social indissociável das demais. O próprio título do livro de Fairclough (2001) publicado no Brasil sublinha estas relações: Discurso e mudança social. A linguagem, como dimensão simbólica, não dá conta da "realidade": não tem o poder de transformá-la, ainda que, dependendo da matriz, possa funcionar na sustentação de formulaçōes apartadas da dimensão material. Como o autor afirma em Language and globalization (2006), há mudanças na vida social que são, em parte, mudanças no discurso sem serem apenas discursivas, ao mesmo tempo em que há mudanças discursivas que podem não apontar para mudanças sociais, como as de motivação retórica. Em síntese, evitar a redução da mudança social ao discurso é tão importante quanto reconhecê-lo como elemento que a constitui.

Assim, a abordagem política pela via da análise crítica do discurso não exclui, antes assume como quadro referencial, as questōes que adquirem materialidade mais espessa do que a da linguagem. É importante insistir que o discurso, em si, mesmo que qualificado como "discurso sobre as tecnologias na educação", não é aqui concebido como determinante único das propostas analisadas, mas como matéria a ser investigada no conjunto das suas condiçôes de possibilidade, comumente postas como performatividade.

Nesse ponto, é importante a caracterização da ideologia no discurso como hegemonia de sentido, esclarecendo que esta "não está circunscrita ao plano do pensamento. $\mathrm{O}$ que faz com que as ideias-chave adquiram performatividade é a congruência dessas disposições de pensamento com a base da vida material" (Barreto \& Leher, 2008, p. 429). Como exemplo, é relevante situar a mercantilização da educação no contexto de abertura do promissor "mercado educacional" às redes 
internacionais. Nesse sentido, o que está em jogo é o deslocamento da educação para o setor de serviços, como a face mais concreta da "comodificação", definida como "processo pelo qual os domínios e as instituiçôes sociais, cujo propósito não seja produzir mercadorias no sentido econômico restrito de artigos para venda, vêm não obstante a ser organizados e definidos em termos de produção, distribuição e consumo de mercadorias" (Fairclough, 2001, p. 255).

Em outras palavras, este texto busca as mediações entre contextos amplos e circunstâncias específicas, através da referência a "discursos nodais, identificados como os que subsumem e articulam muitos outros, inscritos como representações de como as coisas podem ser ("imaginários"), em estratégias para a promoção de mudanças" (Barreto, 2009, p. 21) e, ao mesmo tempo, a eventos discursivos particulares. Portanto, para analisar os discursos oficiais acerca das TIC para a EaD, os marcos regulatórios são nucleares.

No caso das TIC, o sentido hegemônico de "revolução" pode ser considerado emblemático. Citando Barreto e Leher (2008, p. 428):

A suposta revolução é funcional à articulação dos discursos da "sociedade da informação" e da "globalização" em três sentidos: a) permite uma abordagem "técnico-científica" das desigualdades econômicas entre os países, reduzindo-as a uma lacuna ou divisor digital; b) legitima intervenções para "dar assistência aos países que aspiram a superar a lacuna que os separa dos cientificamente avançados" (World Bank, 2002, p. 25); e c) sustenta o rearranjo geoeconômico do planeta, já que "o espelhamento do potencial de mutação informacional no modelo econômico da globalização selvagem converte as separações em apartheid".

O conceito de recontextualização é central, já que, como indica a sua própria designação, as TIC são produzidas em outras relações sociais e com fins diversos. Fairclough (2006, p. 101) a caracteriza como "um fenômeno complexo, envolvendo, para além de uma simples colonização, um processo de apropriação cujas características e resultados dependem das circunstâncias concretas dos diversos contextos". Logo, não pode ser reduzida a "tradução", mesmo considerando a "traiçãa" nela embutida, ou a simples transposição.

Ademais, o processo abrange duas dimensões, como disseminação de discursos além das fronteiras de estrutura e de escala. Fairclough 
(2005) explicita que a primeira envolve o deslocamento de um campo social para outro. Retomando a comodificação, esta não envolve apenas o movimento da comunicação e da informação, mas da lógica dos “negócios” para a educação, com vistas à internacionalização dos "serviços educacionais".

Na dimensão da escala, a recontextualização das TiC pode ser detectada nas formulações das organizações "globais" endereçadas aos Estados nacionais, especialmente quando periféricos, desde que não se perca a perspectiva da complexidade do conceito em leituras lineares e mecânicas, como se o processo não incluísse mediações e condições de possibilidade específicas, detectáveis nos documentos que constituem tentativas de estabelecer marcos regulatórios.

No que diz respeito aos pontos de entrada, os limites deste texto levam à concentração nas escolhas lexicais, ainda que aspectos sintáticos e pragmáticos sejam sublinhados. A abordagem da dimensão semântica pode ser desdobrada em dois movimentos complementares: relexicalização e ressignificação. O primeiro compreende a produção de novos termos, sejam eles neologismos ou transposiçôes dos já cunhados em outras áreas e para outros fins, para dar conta de sentidos que as palavras existentes (supostamente) não expressam. O segundo é constituído pela atribuição de sentidos novos a palavras dicionarizadas, em deslocamentos e/ou esvaziamentos que as inscrevem em matrizes outras. Em conjunto, podem sustentar reconfiguraçôes como a substituição da lógica da produção pela da circulação e do trabalho pela da comunicação (Chauí, 1999), remetendo também à supremacia da comunicação secundária sobre a primária (Zuin, 2006).

\section{Marcos regulatórios}

Para dimensionar a ressignificação da distância, inseparável da aposta nas TIC, são analisados marcos regulatórios que abrangem de documentos legais a formulações que visam à sua aplicação.

\section{Secretaria de Educação a Distância (SEED) - 1995}

É possível afirmar que a recontextualização educacional centrada na formação de professores tem como primeiro marco a Secretaria de 
Educação a Distância (SEED), criada para coordenar as ações ministeriais em relação às TIC: "As metas da SEED são, pois, levar para a escola pública toda a contribuição que os métodos, técnicas e tecnologias de educação a distância podem prestar à construção de um novo paradigma para a educação brasileira" (destaque meu).

O texto prossegue, caracterizando a dimensão paradigmática anunciada nos seguintes termos:

A Secretaria de Educação a Distância - SEED foi criada em dezembro de 1995, coerente com a política global do MEC de compromisso com a qualidade e equidade do ensino público, com a valorização do professor como agente fundamental no processo de ensino-aprendizagem e com o reconhecimento da escola como espaço privilegiado da atividade educacional.

As linhas de ação da SEED fundamentam-se na existência de um sistema tecnológico - cada vez mais barato, acessivel e de manuseio mais simples capaz de:

- trazer para a escola um enorme potencial didático-pedagógico;

- ampliar oportunidades onde os recursos são escassos;

- familiarizar o cidadão com a tecnologia que está em seu cotidiano;

- dar respostas flexíveis e personalizadas para pessoas que exigem diversidade maior de tipos de educação, informação e treinamento;

- oferecer meios de atualizar rapidamente o conhecimento;

- estender os espaços educacionais; e

- motivar os profissionais e alunos para aprenderem continuamente, em qualquer estágio de suas vidas. (Destaques meus)

$\mathrm{Na}$ própria nomeação da Secretaria, o núcleo está identificado à EaD, ainda que o discurso mencione a escola "como espaço privilegiado da atividade educacional”. Por outro lado, a formulação promove a fetichização máxima ao atribuir as ações/transformações listadas a um sistema tecnológico, em deslocamento sintático radical, posicionando as tecnologias no lugar dos sujeitos.

Cabe observar que as formulaçōes transcritas estavam disponíveis até 2005 (http://www.mec.gov.br/seed/linhas.shtm). ${ }^{1}$ Desde então, na página da SEED, é possível verificar o afastamento progressivo dos fundamentos e a ênfase na listagem dos programas e ações. Atualmente, 
esta listagem está associada à "Quantidade de polos da UAB por estado" e à "Lista das IES que integram a UAB", sugerindo o acesso à página específica (http://uab.capes.gov.br/), já que este “item” a extrapola.

\section{Lei de Diretrizes e Bases (LDB) - 1996}

Mesmo sem entrar no mérito do processo que resultou na Lei n. 9.394/96, cabe destacar aqui o modo de inserção da EaD na seção III, artigo 32, parágrafo $4^{\circ}$ : “O ensino fundamental será presencial, sendo o ensino a distância utilizado como complementação da aprendizagem ou em situaçôes emergenciais" (destaques meus).

$\mathrm{O}$ ensino a distância, mais pontual e específico se comparado à educação, mesmo sendo a primeira expressão progressivamente substituída pela segunda, é aqui introduzido pela ressignificação do seu contraponto: aquele que, tal como conhecido e praticado nos mais variados espaços pedagógicos, prescindiria de adjetivação. Assim, é a própria expressão "ensino presencial" que remete à legitimação do ensino a distância.

Esta qualificação (presencial) produz importantes efeitos de sentido. Não deixa de remeter ao apagamento possível em médio prazo, como também instaura de pronto um lugar da diferença: na medida em que o ensino a distância está sempre associado às "novas linguagens", das "novas tecnologias", o presencial pode ser posto como velho, desgastado, sem valor. Nestes termos, a grande novidade discursiva é a expressão cunhada: a qualificação que desqualifica, desgasta, esvazia.

Tratando da formação de professores, o artigo 80 se refere ao incentivo do poder público para o "desenvolvimento e a veiculação de programas de ensino a distância, em todos os níveis e modalidades de ensino, e de educação continuada". Como afirma Giolo (2008, p. 1217), "estendeu ao extremo o alcance da EaD".

Mesmo sem tocar na questionável compatibilidade entre os artigos 80 e 32, bem como nos modos da sua inscrição nas regulamentações que se seguiram, é notório o movimento da LDB no sentido da "flexibilização", nas suas diferentes acepçōes. Retendo o exposto no $1^{\circ}$ parágrafo do artigo $1^{\circ}$ : "Esta Lei disciplina a educação escolar, que se desenvolve, predominantemente, por meio do ensino, 
em instituições próprias", qualificação que, do ponto de vista discursivo, coloca em cena as "impróprias".

\section{Universidade Virtual Pública do Brasil (UNIREDE) - 1999}

A UNIREDE foi um consórcio interuniversitário criado em dezembro de 1999 com o nome de Universidade Virtual Pública do Brasil. Seu lema foi dar início a uma luta por uma política de estado [sic] visando a democratização do acesso ao ensino superior público, gratuito e de qualidade e o processo colaborativo na produção de materiais didáticos e na oferta nacional de cursos de graduação e pós-graduação. (Destaques meus) $)^{2}$

À época da sua criação, foi apresentado como "um canal privilegiado de capacitação do magistério, através da oferta de cursos a distância nos níveis de graduação, pós-graduação, extensão e educação continuada". Um canal previsto nos Objetivos e Metas do Plano Nacional de Educação (PNE) do MEC, aprovado em 2001: "Iniciar, logo após a aprovação do Plano, a oferta de cursos a distância, em nível superior, especialmente na área de formação de professores”. A perspectiva da substituição tecnológica estava explícita em formulações como:

Os materiais educativos de boa qualidade, ao se tornarem independentes da relação presencial, terão sua capacidade de multiplicação tecnológica extraordinariamente aumentada (...). Esta potencialidade de dissociar os processos de ensino da sala de aula faz com que muitos dos processos interativos desta possam ser substituidos pelos meios de comunicação que possibilitam cada vez mais um maior grau de interatividade. (Faria, Leite \& Rondelli, 2000, p. 9; destaques meus)

O histórico ora disponível aponta para a fragilidade da estrutura da UNIREDE, dependente do apoio da Comissão de Educação/ Frente Parlamentar de Educação a Distância da Câmara Federal, dos Ministérios (MEC е МCT) e de órgãos como a Financiadora de Estudos e Projetos (FINEP) e, especialmente, do Conselho Nacional de Desenvolvimento Científico e Tecnológico, através de bolsas para apoiar o desenvolvimento da UNIREDE nos polos. Ainda que o Comitê Gestor e os conselhos não tenham logrado o êxito pretendido, fica o registro 
da tentativa de coordenar as açôes relativas à EaD no âmbito das universidades públicas.

4. Grupo de Trabalho Interministerial, ${ }^{3}$ instituido pelo Decreto Presidencial de 20/10/2003, encarregado de analisar a situação das universidades e apresentar plano de reforma

É possível afirmar que o diagnóstico e a proposta apontam para a "revisão do marco regulatório do ensino superior" (p. 16), em pleno acordo com as determinaçóes dos organismos internacionais para a periferia do capitalismo. Entre as linhas mestras para o "redesenho" das universidades, o documento focaliza a EaD como forma de atender às diferentes dimensões do modelo neoliberal defendido: (a) diminuir significativamente o número de professores e duplicar o número de alunos; (b) baratear drasticamente os custos das universidades; e (c) deslocar o foco da formação para o seu produto, desde que sejam utilizados testes adequados para aferir as competências-alvo, traduzidas nos "materiais educacionais que garantam larga utilização" (p. 14), disponíveis em polos descentralizados.

Nessa perspectiva, a citação a seguir é emblemática do "desinvestimento" na universidade pública, assim como a aposta na substituição tecnológica:

É imperativo reconhecer que a universidade pública brasileira, nos limites impostos pela educação presencial, mesmo com aumento substancial de recursos, não teria condiçôes de aumentar as vagas de forma maciça no curto e media [sic] prazos [nem] adaptar-se a realidade de um tempo onde o conhecimento se espalha no mundo, por internet, televisão e outras modernas formas de mídia, sem respeitar o tradicional locus histórico do aprendizado em sala de aula. (p. 13-15; destaques meus)

\section{Fórum das Estatais pela Educação: Universidade Aberta do Brasil $(U A B)-2005^{4}$}

As condições necessárias à implantação das medidas propostas exigiam estrutura ao mesmo tempo forte e dotada de maior abrangência e flexibilidade do que a "muito interessante experiência (...) rede de Universidades Públicas (UNIREDE)” (p. 10). Assim, é desenhada a 
$\mathrm{UAB}$, no âmbito do projeto elaborado pelo Fórum das Estatais pela Educação, para "promover uma interação mais ampla, seja atuando também com empresas que não são exclusivamente estatais, assim como com demais instituições de educação superior, sejam públicas, sejam privadas" (destaques meus). Na mesma página do documento, as condições de operação são explicitadas:

A estrutura básica da UAB e dos Consórcios deve se assemelhar mais a uma "fábrica", enfatizando a alta produção de cursos (planejamento curricular e pedagógico; preparação de roteiros de cursos; produção audiovisual; de textos de acompanhamento; atendimento a suporte ao aluno; avaliação do aluno e do curso), via várias formas tecnológicas. (Destaques meus)

O documento sublinha, entre as parcerias previstas, o reforço representado pela "participação da CAPES, marcando sua presença no ensino e na pesquisa em EaD” (p. 5), referindo-se à demanda induzida pelo Programa de Apoio à Pesquisa em Educação a Distância (PAPED). ${ }^{5}$ Remete, no seu conjunto, às condições de exequibilidade da política de EaD pela UAB, antecipando medidas e garantias.

\section{Universidade Aberta do Brasil (UAB)/Coordenação de Aperfeiçoamento de Pessoal de Nivel Superior (CAPES) - 2007}

Para consolidar a proposta da UAB, foi promulgada a Lei n. 11.502 , de 11 de julho de 2007, reestruturando-a como "nova" CAPES, de modo a não apenas incluí-la institucionalmente, mas a conferir-lhe uma espécie de selo de qualidade.

Do ponto de vista da reestruturação da CAPES, é aqui destacada a criação da Diretoria de Educação Básica Presencial (DEB), na medida em que, tal como ocorreu na $\mathrm{LDB}$, a adjetivação aponta para a possibilidade de legitimação da "educação básica a distância", como preenchimento do espaço entre os artigos 32 e 80 da referida Lei, até pelas ressignificações de complementação e emergência nos discursos acerca da crise educacional a ser superada.

Do ponto de vista da UAB, como programa da Diretoria de Educação a Distância (DED) em parceria com a SEED, é importante assinalar que o seu portal ${ }^{6}$ está centrado no elogio das "fortes parcerias" e nas questóes operacionais envolvidas, como o "apoio de pontos 
estrategicamente localizados”, privilegiando a dimensão técnica, expressa, entre outras páginas, pelo modelo de Polo de Apoio Presencial. Sua "Apresentação"7 é feita nos seguintes termos:

O Sistema Universidade Aberta do Brasil (UAB) tem como prioridade a formação de professores para a Educação Básica. Para atingir este objetivo central a UAB realiza ampla articulação entre instituições públicas de ensino superior, estados e municípios brasileiros, para promover, através da metodologia da educação a distância, acesso ao ensino superior para camadas da população que estão excluídas do processo educacional. (Destaque meu)

Sua origem no "Fórum das Estatais pela Educação com foco nas Políticas e a Gestão da Educação Superior” é assumida, sem que aspectos substantivos também o sejam. Resta, na página citada, o enunciado: "Tendo por base o aprimoramento da educação a distância, o Sistema UAB visa expandir e interiorizar a oferta de cursos e programas de educação superior".

A base, portanto, está inscrita no "discurso da democratização do acesso ao ensino superior”, sem projeto pedagógico explícito, conferindo centralidade ao "aparato tecnológico e seu uso como os responsáveis diretos pela qualidade ou não do processo educativo" (Dourado, 2008, p. 905). Por outro lado, no movimento de analisar esta centralidade, é fundamental destacar que a ausência de explicitação de um projeto pedagógico não implica um vazio, mas filiação a ser investigada a partir dos seus pressupostos. Entre estes, merece destaque, de novo, a redução das TIC à EaD. Sem desconsiderar o fato de que as primeiras viabilizam o boom da última, o que não pode ser deixado à margem são as recontextualizações das TIC, assumindo-se que o acesso a elas não implica um uso singular, mas usos, no plural, indissociáveis das relações entre os modos de acesso e as propostas de "democratização" da informação e do conhecimento, sugerindo mais uma equivalência simplificadora.

\section{Sistema Nacional de Formação de Profissionais do Magistério da} Educação Básica - 2009

A redução das TIC à EaD, bem como a ênfase conferida a esta última, prevista na equação formulada pelo GT Interministerial, tem 
significado descaso para com a formação inicial presencial, parecendo concentrar os esforços em estratégias de formação continuada. Sem negar o valor desta última, não faz sentido projetá-la como preenchimento de lacunas a serem deixadas, em uma espécie de adiamento também relacionado à perspectiva da substituição da formação pela certificação.

Nesse sentido, a proposta de uma política nacional de formação de professores pode representar impulso no sentido do preenchimento de lacunas. Por outro lado, as simplificações constitutivas dos marcos regulatórios aqui referidos também podem significar nivelamento por baixo, em aligeiramento favorecedor de uma "semiformação" associada a formas e representações de uma "aprendizagem turbo" (Zuin, 2009).

Para encaminhar estas reflexões, é importante reconhecer o hibridismo que caracteriza o discurso do Decreto n. 6.755, de 29 de janeiro de 2009, que "disciplina a atuação da Coordenação de Aperfeiçoamento de Pessoal de Nível Superior - CAPES no fomento a programas de formação inicial e continuada, e dá outras providências". ${ }^{8} \mathrm{O}$ texto em questão justapõe formulações inscritas em matrizes diversas, como: o princípio da "articulação entre a teoria e a prática no processo de formação docente, fundada no domínio de conhecimentos científicos e didáticos, contemplando a indissociabilidade entre ensino, pesquisa e extensão"; os objetivos de "ampliar o número de docentes atuantes na educação básica pública que tenham sido licenciados em instituições públicas de ensino superior, preferencialmente na modalidade presencial" e de "promover a atualização teórico-metodológica nos processos de formação dos profissionais do magistério, inclusive no que se refere ao uso das tecnologias de comunicaçãao e informação nos processos educativos"; e a ação de induzir a oferta de cursos de formação continuada que "integrarão o acervo de cursos e tecnologias educacionais do Ministério da Educação”.

O discurso híbrido e o estágio de construção deste Sistema Nacional não autorizam muitas conclusões. Por outro lado, suas relaçóes com programas como o REUNI e o PROUNI, não diretamente ligados à utilização das TIC para a EaD, mas presentes no arcabouço do projeto, remetem à ressignificação de propostas de democratização do acesso ao ensino superior e, através de parcerias público-privadas (PPP), favorecem o apagamento das fronteiras entre as duas esferas. 


\section{Entre o público e o privado}

Como as relações expressas no título deste texto supõem a demarcação de fronteiras entre o público e o privado, cabe aqui o registro de um deslocamento da noção específica. Afinal, quer esta relação seja posta como "simbiose" (Silva \& Souza, 2009, p. 779), quer como mudanças nos mecanismos institucionais de regulação dos sistemas educativos estatais (Dale, 1994), entre as quais Peroni, Oliveira e Fernandes (2009) destacam a alteração da propriedade (público não estatal) e a permanência da propriedade estatal investida da lógica do mercado, não há como negar os efeitos produzidos pela comodificação educacional.

No contexto brasileiro, este movimento é intensificado pela sua articulação ao Projeto de Inovação Tecnológica. Este último substantivo, que passa a ser necessariamente agregado à ciência e tecnologia, tem como expressão mais concreta uma política de financiamento que remete à desqualificação da universidade como "espaço público de produção de conhecimento" (Leher, 2004, p. 886). A adoção da lógica do mercado no encaminhamento das questôes educacionais tem implicado, com a redução das TIC à EaD, condiçôes objetivas favorecedoras da transformação da educação em mercadoria (Oliveira, 2009). Tem sido notória a voracidade com que o mercado abocanha diversas fatias de um ensino superior reduzido a terciário, no movimento de deslocar o sentido social da educação para a condição de mercadoria negociável no mercado.

No caso da EaD, não apenas o número de vagas oferecidas dobrou em apenas dois anos, como sua distribuição foi drasticamente alterada. Sua oferta por instituições públicas, que não alcançava 5\% do total em 2006 (Sguissardi, 2008), agora compete numericamente. Conforme o JC E-mail n. 3824, de 11 de agosto de 2009, são "1,5 milhão de vagas em 145 instituições, cerca de 70 das quais públicas". ' Foram, sucessivamente, apagadas as fronteiras entre o público e o privado nos sete marcos regulatórios aqui focalizados, com a recontextualização das TIC como estratégia de controle dos mais diversos espaços.

Sendo redimensionada para incorporar e chancelar a UAB, a CAPES, como marco da avaliação em nível de pós-graduação no contexto nacional, pode, através da orientação técnica, remeter a controle 
centralizado para um nivelamento questionável, em vários sentidos. Um deles está associado à indefinição do papel dos diferentes parceiros (Secretarias de Educação Básica e Superior, de um lado, e Secretaria de Educação a Distância, de outro) na empreitada, considerando as relações entre educação presencial e a distância em termos de expansão e qualidade do ensino superior.

Apenas para citar um exemplo, havia um documento que deveria regular a expansão da EaD: "Referenciais de qualidade para educação superior a distância", ${ }^{10}$ cuja primeira versão foi elaborada em 2003. Agora são propostos "Referenciais Nacionais dos Cursos de Graduação", 11 avançando sobre a autonomia universitária em nome da uniformização. Assim, é razoável supor que: a incorporação das TIC continue direcionada à $\mathrm{EaD}$; as avaliaçóes tragam resultados mais satisfatórios porque condizentes com parâmetros curriculares veiculados por "materiais educacionais que garantam larga utilização"; e as relações definidoras das estratégias de expansão através do ensino presencial ou a distância sejam minimizadas. Daí a importância da análise das implicações dos encaminhamentos assumidos nas políticas em curso.

\section{Assim no público como no privado?}

Nos limites deste texto, considerando a cadeia de simplificações que têm marcado as relações entre as TIC e a EaD, com ênfase no questionamento do estatuto de modalidade atribuído à última, concentro-me nas implicações relativas a trabalho e formação docente. Para tanto, parto da aposta absoluta nos "pacotes tecnológicos" que, supostamente autoexplicativos, dispensariam quaisquer mediações pedagógicas. $\mathrm{O}$ acesso a eles resolveria as mais diversas questóes educacionais, em uma formulação que tende a não tocar nas questões relativas ao próprio acesso: das condiçôes materiais às possibilidades e sentidos de que estes são investidos. Assim, de elementos constitutivos das práticas pedagógicas, os materiais veiculados nos "pacotes" passam a ser tomados pela totalidade, em processo metonímico que materializa a incorporação das TIC como estratégia de substituição tecnológica: as TIC postas em vez de...

As condições de possibilidade desta estratégia são sustentadas pelo imaginário caracterizado por Mattelart (2002) nos seguintes 
termos: “a segunda metade do século xx foi marcada pela formação de crenças no poder miraculoso das tecnologias informacionais" ( $p$. 172), no "discurso salvador sobre a promessa de concórdia universal, de democratização descentralizada, de justiça social e de prosperidade geral” (p. 31), na convergência dos discursos apologéticos para "atestar o final dos grandes determinantes sociais e econômicos na construção dos modelos de implantação das tecnologias digitais e de suas redes” (p. 146). Este imaginário é constituído pela articulação de dois discursos nodais e representado como "sociedade global da informação" (Barreto, 2009), em um processo de comodificação que, ultrapassando a materialidade discursiva, também é sustentado pela intensa negociação de ações do Sistema Educacional Brasileiro privado na Bolsa de Valores. ${ }^{12}$

Para tentar dar conta do conjunto de questôes envolvidas, proponho que a análise extrapole a distinção formal entre ensino presencial e a distância, achatamentos derivados de oposição simplista, reforçados pelo recurso à qualificação "semipresencial" para o preenchimento dos espaços entre eles. A intenção é favorecer a captação de aspectos que extrapolam recortes meramente operacionais, em direção às diferentes condições em que a recontextualização das Tic é produzida, quer em nível macro, quer em micro.

Em outras palavras, se concentrada nas "modalidades" presencial e a distância, a análise pode deixar de fora aspectos substantivos da estratégia de substituição tecnológica sustentada pela perspectiva determinista e desenhada nos limites da razão instrumental, reduzindo os sujeitos à condição de usuários da informação disponível, no sentido de já produzida e não protegida por patentes e leis de propriedade intelectual. Dessa forma, são negadas condições favoráveis de incorporação das TIC ao trabalho escolar, nas suas múltiplas dimensóes. Resta o fetiche de que, uma vez presentes, elas resolveriam todos os problemas da educação.

Este enredo, que pode ser compreendido a partir do imaginário já referido, sem se restringir a ele, é engendrado por formulaçôes que giram em torno de equipar escolas, professores e alunos. Hoje, programas oficiais, em diferentes níveis, envolvem financiamento facilitado ou mesmo a distribuição de equipamentos com vistas à melhoria da educação: computadores de mesa e, especialmente, laptops. A aposta é a 
de que a presença das TIC seja condição suficiente para promover esta melhoria, com base nas duas inversões discutidas por Chauí (1999) e já apontadas neste texto: a substituição da lógica da produção pela da circulação e da lógica do trabalho pela da comunicação. Assim, também na educação, vale a lógica do mercado: quanto maior a presença da tecnologia, menor a necessidade do trabalho humano, bem como maior a subordinação real do trabalho ao capital e aos que se valem das tecnologias para ampliar as formas de controle do trabalho e dos seus produtos.

$\mathrm{Na}$ tentativa de esclarecer a estratégia em questão, é relevante pontuar as duas modalidades de substituição em jogo: a total e a parcial. Na primeira, radical, estão cada vez mais estruturadas propostas de ensino a distância, especialmente para a formação de professores. $\mathrm{Na}$ segunda, a substituição assume configurações mais sofisticadas e menos visíveis, na medida em que, com a centralidade deslocada para as TIC, tendem a se materializar como programas de capacitação e treinamento para o seu uso "adequado". O professor não é exatamente retirado da cena, mas relegado a um papel secundário, sendo suas açôes tentativamente reduzidas a aspectos como o tempo necessário à execução de tarefas determinadas. Em ambos os casos, no movimento de expansão-redução, é estabelecida uma relação direta, quando não automática, entre TIC e aprendizagem.

Nos termos aqui analisados, a presença maciça das TIC tem remetido ao esvaziamento do trabalho e da formação docente, partindo do determinismo e chegando à substituição tecnológica, tanto no ensino a distância quanto no presencial, seja na esfera privada, seja na pública, em uma aproximação a ser considerada nas análises concernentes a expansão e qualidade.

Recebido em fevereiro de 2010 e aprovado em março de 2010.

\section{Notas}

1. Mais precisamente até o Seminário "EaD em debate: a experiência UfEs" (16/9/2005), conforme compromisso de mudança assumido pelo então diretor de Política em EaD do MEC. Disponível em: <http://www.neaad.ufes.br/informes_2005/imagens/seminario_ead_ tabela.jpg >. Acesso em: $1^{\circ}$ out. 2009.

2. Disponível em: <http://www.unirede.br/index.php?option=com_content\&view=article\&id= 43\&Itemid=27>. Acesso em: 11 out. 2009. 
A formação de professores a distância como estratégia de expansão do ensino superior

3. "Bases para o enfrentamento da crise emergencial das universidades federais e roteiro para a Reforma Universitária brasileira". Brasília, DF: [s.n.], 15 dez. 2003. Disponível em: <http://www.andes.org.br/anexo-circ021-04.doc>. Acesso em: 10 set. 2009.

4. Disponível em: <http://portal.mec.gov.br/arquivos/pdf/universidade.pdf>. Acesso em: 15 out. 2009.

5. Programa de Apoio à Pesquisa em Educação a Distância. Parceria SEED-CAPES, com o apoio da UNESCO. Disponível em: <http://paped.proinfo.mec.gov.br/>. Acesso em: 11 out. 2009.

6. Disponível em: <http://uab.capes.gov.br>. Acesso em: 20 jul. 2009.

7. Disponível em: $<$ http://uab.capes.gov.br/index.php?option=com_content\&view=article\&id= $111 \&$ Itemid=27>. Acesso em: 20 jul. 2009.

8. Disponível em: <http://www.jusbrasil.com.br/legislacao/92458/decreto-6755-09>. Acesso em: 11 out. 2009.

9. Disponível em: <http://www.jornaldaciencia.org.br/Detalhe.jsp?id=65295>. Acesso em: 22 out. 2009.

10. Disponível em: $<$ http://portal.mec.gov.br/index.php?option=com_content\&view=article\&id= $12777 \% 3$ Areferenciais-de-qualidade-para-ead $\&$ catid $=193 \% 3$ Aseed-educacao-a-distancia $\&$ Itemid=865>. Acesso em: 10 out. 2009.

11. Disponível em: $<$ http://portal.mec.gov.br/index.php?option=com_content\&view=article\&id= $13812 \&$ Itemid $=86>$ Acesso em: 28 out. 2009.

12. A primeira página de Economia do jornal $O$ Globo, de 16 de agosto de 2010 (p. 19), com a manchete "Lucro que vem das salas de aula", noticia que o "setor privado de educação brasileiro atrai investidores estrangeiros e já registra um total de operações de aquisição de R \$1,9 bilhão", trazendo um quadro das últimas operações, mostrando o salto de 41 milhões em junho deste mesmo ano para 72,5 milhões em agosto.

\section{Referências}

ANTUNES, R.; BRAGA, R. (Org.). Infoproletários: degradação real do trabalho virtual. São Paulo: Boitempo, 2009.

BARRETO, R.G. Discursos, tecnologias, educação. Rio de Janeiro: EDUERJ, 2009.

BARRETO, R.G.; LEHER, R. Do discurso e das condicionalidades do Banco Mundial, a educação superior "emerge" terciária. Revista Brasileira de Educação, Campinas, n. 39, p. 423-436, set./dez. 2008.

CHAUÍ, M. Ideologia neoliberal e universidade. In: Oliveira, F; PaOli, M.C. (Org.) Os sentidos da democracia: políticas do dissenso e hegemonia global. Petrópolis: Vozes; Brasília, DF: NEDIC, 1999. p. $27-51$. 
DOURADO, L.F. Políticas e gestão da educação superior à distância: novos marcos regulatórios? Educação \& Sociedade, Campinas, v. 29, n. 104, p. 891-917, out. 2008.

FAIRCLOUGH, N. Discurso e mudança social. Brasília, DF: UNB, 2001. FAIRCLOUGH, N. Analysing discourse: textual analysis for social research. London: Routledge, 2003a.

FAIRCLOUGH, N. Critical discourse analysis in researching language in the new capitalism: overdetermination, transdisciplinarity and textual analysis. 2003b. Disponível em: <http://www.ling.lancs.ac.uk/ staff/norman/2003b.doc>. Acesso em: 10 jan. 2008.

FAIRCLOUGH, N. Blair's contribution to elaborating a new 'doctrine of international community'. Journal of Language and Politics, Lancaster, v. 4, n. 1, p. 41-63, 2005.

FAIRCLOUGH, N. Language and globalization. London: Routledge, 2006.

FAIRCLOUGH, N. A dialectical-relational approach to critical discourse analysis in social research. In: WodAK, R.; MeYER, M. (Ed.). Methods in critical discourse analysis. London: Sage, 2009. p. 121-138.

FAIRCLOUGH, N. A dialética do discurso. Teias, Rio de Janeiro, v. 11, n. 22, 2010. Disponível em: <http://www.periodicos.proped.pro.br/ index.php?journal=revistateias $>$. Acesso em: 12 set. 2010.

FARIA, D.S.; LEITE, S.D.; RONDELLI, E. UNIREDE: um projeto estratégico para a educação superior. Disponível em: <http://ftp.unb.br/ pub/unB/ipr/rel/parcerias/2000/1912.pdf>. Acesso em: 15 out. 2009.

GIOLO, J. A educação à distância e a formação de professores. Educação \& Sociedade, Campinas, v. 29, n. 105, p. 1211-1234, set./dez. 2008.

LEHER, R. Para silenciar os campi. Educação \& Sociedade, Campinas, v. 25, n. 88, p. 867-891, out. 2004.

MATTELART, A. História da sociedade da informação. São Paulo: Loyola, 2002. 
MATTELART, A. Para que "nova ordem mundial da informação"? In: Moraes, D. (Org.). Sociedade midiatizada. Rio de Janeiro: Mauad, 2006. p. 233-246.

OLIVEIRA, R.P. A transformação da educação em mercadoria no Brasil. Educação \& Sociedade, Campinas, v. 30, n. 108, p. 739-760, out. 2009.

PERONI, V.M.V.; OLIVEIRA, R.T.C.; FERNANDES, M.D.E. Estado e terceiro setor: as novas regulações entre o público e o privado na gestão da educação básica brasileira. Educação \& Sociedade, Campinas, v. 30, n. 108, p. 761-778, out. 2009.

SGUISSARDI, V. Modelo de expansão da educação superior no Brasil: predomínio privado/mercantil e desafios para a regulação e a formação universitária. Educação \& Sociedade, Campinas, v. 29, n. 105, p. 991-1022, set./dez. 2008.

SILVA, M.V.; SOUZA, S.A. Educação e responsabilidade empresarial: "novas" modalidades de atuação da esfera privada na oferta educacional. Educação \& Sociedade, Campinas, v. 30, n. 108, p. 779-798, out. 2009.

WOOD, E.M. Democracia contra capitalismo: a renovação do materialismo histórico. São Paulo: Boitempo, 2003.

ZUIN, A.A.S. Educação a distância ou educação distante?: o Programa Universidade Aberta do Brasil, o tutor e o professor virtual. Educação \& Sociedade, Campinas, v. 27, n. 96, p. 935-954, out. 2006.

ZUIN, A.A.S. Itinerário histórico da comunicação e da formação. Palestra proferida no PROPED-UERJ, em 17 set. 2009. 